\title{
Linking inundation timing and extent to ecological response models using the Murray-Darling Basin Floodplain Inundation Model (MDB-FIM)
}

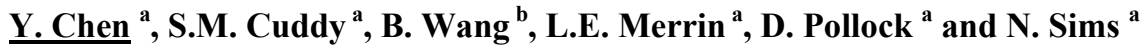 \\ ${ }^{a}$ CSIRO Land and Water, Canberra ACT 2601, Australia \\ Email:yun.chen@,csiro.au \\ ${ }^{b}$ Forestry College, Inner Mongolia Agricultural University, Hohhot 010019, China
}

\begin{abstract}
In recent decades, the ecological condition of the Murray-Darling Basin of eastern Australia has been in focus as the effects of drought and long-term over-extraction have resulted in a stressed, degraded river system. Within the Basin, the climate is highly variable (seasonally and decadally), the river system is highly regulated with large storages in the headwaters of most catchments, and regulation of flows is dominated by irrigation demands, both in terms of volume and timing. While many of the catchments have some environmental flow rules built into the river operations, these have been, in the main, ineffective in maintaining or improving condition. The recent long-term drought has exacerbated the situation, with irrigators and environmental assets alike suffering from reduced, and unreliable, water allocations. The Australian Government has been responsive to these concerns and has mandated the development of a Basin Plan to protect, restore and provide for the ecological values and ecosystem services of the Basin, without unduly compromising the net economic returns to the Australian community from the use and management of the Basin water resources. The requirement to balance the triple bottom-line - namely environmental, social and economic - means that the benefits from returning water to the environment, especially if it is at the expense of other uses, must be quantifiable and realisable. This requires an understanding of the relationship between the wetting requirements of water-dependent ecosystems; and the ability of the river system (and its management) to deliver water, in-channel and overbank, in a way (timing and volume) that is informed by these needs.
\end{abstract}

The Murray-Darling Basin Floodplain Inundation Model (MDB-FIM) maps spatial extent of floodplain inundation under ecologically significant flood return periods to derive spatial inundation patterns over time across the Murray-Darling Basin under different climate and development scenarios. Model development, as a proof-of-concept, is reported in Doody et al. (2009). Such a model can be extended to provide the spatial framework for implementing floodplain ecohydrology models that predict the likely ecological response of a selected set of key habitats, assets and/or regions from changes in flow, expressed as average flow return periods.

This paper reports on the initial phase of such an application. A project commenced to enumerate the environmental, social and economic benefits of returning water to the environment as prescribed in the Basin Plan, under a range of alternate flow scenarios. MDB-FIM was selected as a candidate foundation framework to provide the spatial relationships between river volumes and ecologically-relevant flood return periods as commonly used when expressing environmental water requirements. The first stage involved re-processing the MDB-FIM input data to include recent flood events (2010-2011). This extends MDB-FIM's spatial coverage to include many high floodplains that had not been inundated for many decades. In other words, this enhances MDB-FIM's ability to underpin the development of ecological response models for such areas which typically have different vegetation communities to low floodplains and riparian zones. The second stage required working with ecologists and hydrologists to match MDB-FIM's spatial and temporal resolutions with that required by the ecological response models. It is anticipated that the use of MDB-FIM will provide for a whole-of-Basin quantitative assessment of floodplain ecosystems and environmental assets. This in turn can be used to support the assessment of the benefits of returning water to these environments.

Keywords: floodplain, ecosystem, ecohydrology, MDB-FIM, flood return period, annual recurrence interval 


\section{BACKGROUND}

\subsection{Overview}

In recent decades, the ecological condition of the Murray-Darling Basin (MDB) has been in focus as the effects of drought and long-term over-extraction have resulted in a stressed, degraded river system. Within the Basin, the climate is highly variable (seasonally and decadally), the river system is highly regulated with large storages in the headwaters of most catchments, and regulation of flows is dominated by irrigation demands, both in terms of volume and timing. While many of the catchments have some environmental flow rules built into the river operations, these have been, in the main, ineffective in maintaining or improving condition. The recent long-term drought has exacerbated the situation, with irrigators and environmental assets alike suffering from reduced, and unreliable, water allocations. The Australian Government has been responsive to these concerns. In 2002, it established The Living Murray program to restore the River Murray system, including return of water to the river and its environs. This has been followed by the development of the Basin Plan which is mandated under the Water Act 2007 to 'protect, restore and provide for the ecological values and ecosystem services of the Basin' (S3d(ii)), 'without unduly compromising the net economic returns to the Australian community from the use and management of the Basin water resources' (S3d(iii)). The requirement to balance the triple bottom-line - environmental, social and economic - means that the benefits from returning water to the environment, especially if it is at the expense of other uses, must be quantifiable and realisable. This requires an understanding of the relationship between the wetting requirements of water-dependent ecosystems; and the ability of the river system (and its management) to deliver water, in-channel and overbank, in a way (timing and volume) that is informed by these needs.

Balancing the triple-bottom line also requires the development of tools and systems that can link the passage of water through the river system (rainfall, runoff, storage, regulation, and release) with response models (environmental, social and economic) to provide quantifiable measures of return on investment from a range of alternate water management strategies. A modelling exercise commenced to enumerate the environmental, social and economic benefits of returning water to the environment as prescribed in the Basin Plan, under a range of water management options. Within the context of the project discussed here, water management strategies are instantiated as sets of 114-year daily flow files for hundreds of instream locations throughout the Basin. These data are the output from river system models that are used for water planning by state and federal water managers and several sets of flow time series (simulating current and proposed water sharing and extraction limits) have been available for evaluation of ecological and socio-economic impacts. Considering data availability and the time and resource constraints of the project, a traditional scenario analysis approach was adopted. While it is not possible to report on the results of the project at this time, some of the key environmental assessment components are described in the section below, with the focus of the following sections of this paper being on the use of a floodplain inundation model to provide the spatial and temporal framework linking the water management scenarios with models of ecological response to those scenarios.

\subsection{Ecological Response Modelling}

Predicting the outcome from returning water to the environment is a significant challenge, not least because we have limited understanding of ecological response to unary and multiple, interacting pressures and stimuli; but also because it is difficult to find scalable indicators and/or measures that adequately describe response in terms that are meaningful against short-, medium- and longer-term aspirations. Scale (temporal, spatial and operational) is a confounding factor, as is cumulative impact.

Ecological response models seek to predict change in state, at local or habitat scale, as a consequence of one or more external stimuli (e.g. changes in rainfall, temperature). The ecological component of interest is thus conceptualized in relation to the stimuli. Taking inundation as an example, we can then describe relationships (depending on the richness of the underlying evidence) such as 'this vegetation type needs to be inundated to depth $\mathrm{x}$ for duration $\mathrm{y}$ every $\mathrm{z}$ years to ensure germination. Modelling this relationship would require predictions of inundation magnitude (spatial extent), depth (flow volume), and duration (length of inundation) which summarise complex hydrological flow data. A common measure of changes in flow that is relevant to how environmental water requirements are expressed is average return interval, i.e. flood return period. Quantifying ecological outcomes of flow scenarios is then possible through linking flow scenarios to a floodplain inundation model, such as the Murray-Darling Basin Floodplain Inundation Model (MDB-FIM) developed by Doody et al. (2009). 


\subsection{MDB-FIM}

The MDB-FIM maps spatial extent of floodplain inundation under ecologically significant flood return periods to derive spatial inundation patterns over time across the Basin under different climate and development scenarios. The development and use of the products for this purpose has been reported in Doody et al. (2009) and Overton et al. (2011). Such a model can be extended to provide the spatial framework for implementing floodplain ecohydrology models that predict the likely impact of changes in flow, expressed as average return intervals (ARIs) of particular flow events, on ecological response. For this reason, MDB-FIM is being trialed by the project team to provide the spatial relationships between river volumes, ecologically-relevant flood return periods (expressed as average return and patterns of inundation).

The first stage involved updating MDB-FIM to include recent flood events (2010-2011). This extends MDBFIM's spatial coverage to include many high floodplains that had not been inundated for many decades. In other words, this enhances MDB-FIM's ability to underpin the development of ecological response models for such areas which typically have different vegetation communities to low floodplains and riparian zones. The second stage required working with ecologists and hydrologists to match MDB-FIM's spatial and temporal resolutions with that required by the ecological response models. It is anticipated that the use of MDB-FIM will provide for a whole-of-Basin quantitative assessment of floodplain ecosystems and environmental assets. This in turn can be used to support the assessment of the benefits of returning water to these environments. This paper reports some primary results of the project.

\section{METHODOLOGY}

MDB-FIM is designed to compare spatial patterns of inundation likely under different flow scenarios: usually a flow scenario approximating an historical or 'without-development' flow regime (i.e. without regulatory structures or management); and one or more alternate flow scenarios being evaluated.

Firstly, the Basin was divided into 95 ecohydrological zones. Each was associated with one or more flow gauging stations for which good medium- to long-term observed data were available. For those ARIs relevant to the ecological response models (typically 1 -in-1, 1-in-2, 1-in-5 and 1-in-10 years) a 'peaks-over-threshold' partial series analysis technique was applied to the flood frequency analysis for generating zonal return period curves (RPCs). These RPCs were then used to quantify ARI flows for each scenario within each ecohydrological zone.

Inundation extent maps were derived from the high temporal frequency of MODIS images (MOD09A1 collection 5) captured from 18 February 2000 to 5 August 2011 showing surface reflectance at 500m pixel resolution composited over an 8-day period (USGS, 2010). Inundation in each image was detected using an Open Water Likelihood (OWL) index, developed from the MOD09A1 data, which is based on a combination of the Enhanced Vegetation Index (Huete et al., 2002) and the Global Vegetation Moisture Index (Ceccato et al., 2002). OWL pixel values represent the probability of the presence of standing water within a MODIS pixel (Kirby et al., 2008). Further details of the OWL method can be found in Guerschman et al. (2009).

ARI flow rates for each scenario for each zone were then matched with one or more similar flow rates in the observed daily flow (giving dates for selecting the ARI inundation extent maps from the MODIS imagery), noting that this approach is restricted to those ARI flow rates that were observed during the period of the MODIS imagery. In other cases (i.e. when the ARI flow rate was not observed between 2000 and 2011), other GIS inundation layers, such as RiM-FIM (Overton et al., 2006; Penton and Overton, 2007), were used to fill the gaps. In this way, maps of inundation extent for each ARI for each zone under each scenario were created, and then composited into ARI maps for the whole of the Basin. The methodology of MDB-FIM is outlined in Figure 1. The original model development can be found in Overton et al. (2011).

\section{OUTPUTS AND DISCUSSION}

\subsection{Inundation Extent and Pattern}

A series of inundation extent maps were generated for the Basin that show the spatial pattern and area inundated for each ARI under each flow scenario. A comparison of inundation extent between flow scenarios can then be made and presented as a numeric change in inundation area or maps of change in inundation area.

While the maps in Figure 2 and Figure 3 provide spatial patterns of inundation extent, the statistics derived from them (Table 1 and Figure 4) provide a measure of inundation area. Both are required as a basis for ecological response modelling. Spatial data of known habitats of ecological components such as vegetation, birds, frogs, can be overlaid on the floodplain inundation areas to derive critical information on targeting 
specific aims for allocation of environmental water to prevent decline of ecosystems. It is anticipated that the results can potentially allow stakeholders to consider the impact of management flow regimes used in the past and perhaps determine new and more beneficial regimes into the future, which have the ability to improve the health of multiple components within a floodplain ecosystem.

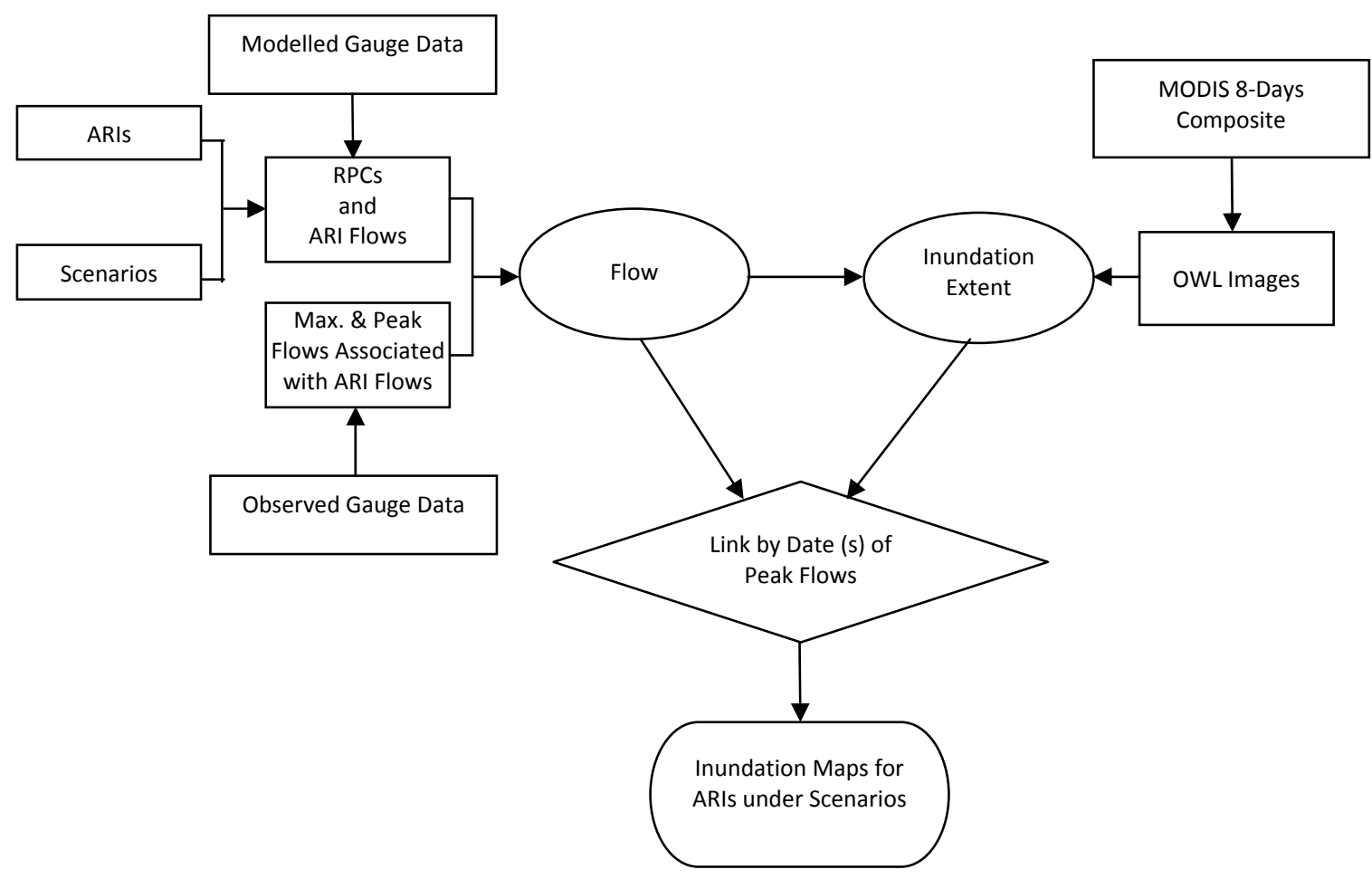

Figure 1. Flowchart of MDB-FIM methodology.
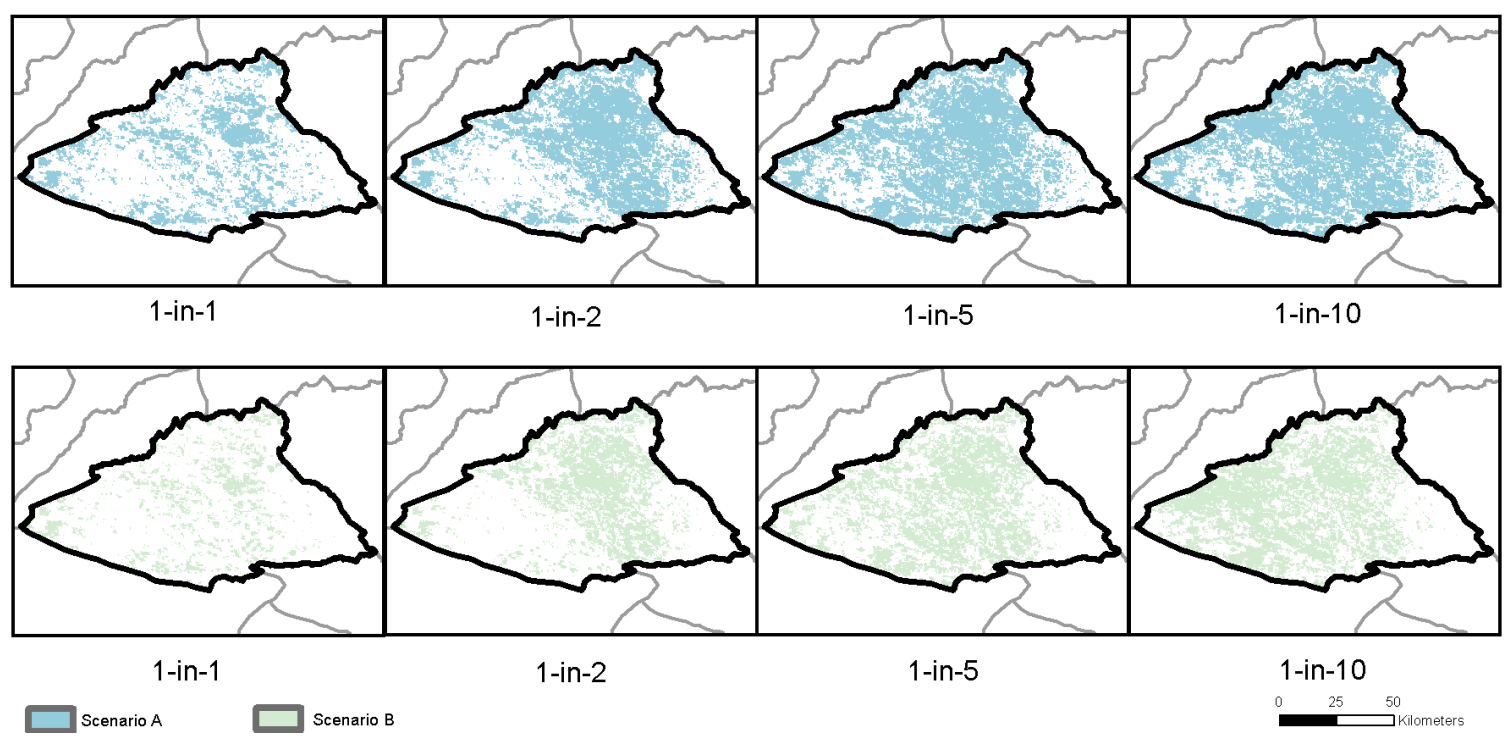

Figure 2. Maps of inundation extent for four ARIs (1-in-1, 1-in-2, 1-in-5 and 1-in-10 years) under two flow scenarios (here identified as Scenarios A and B) for an MDB-FIM ecohydrological zone. 


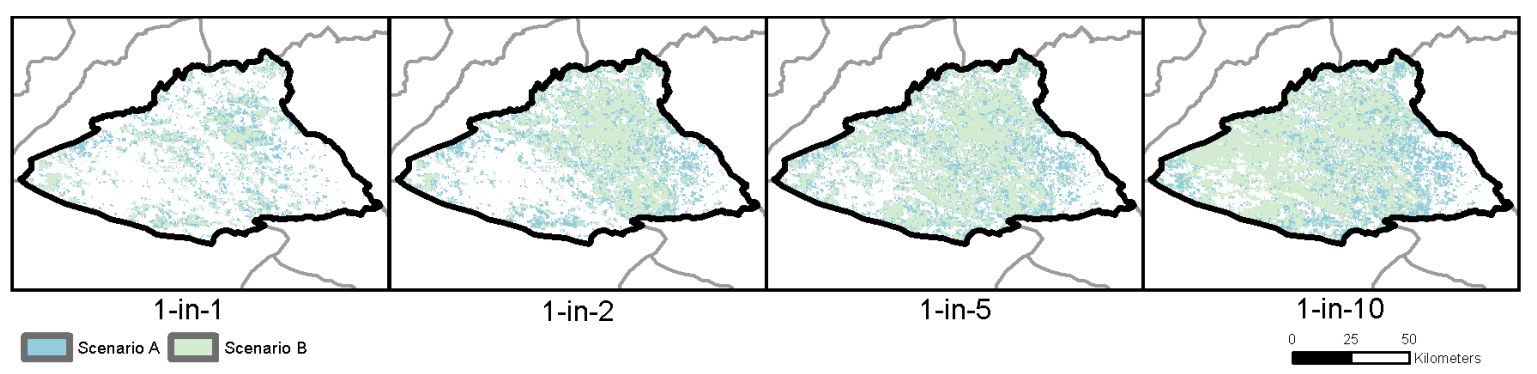

Figure 3. Maps of change in inundation extent for the ARIs, scenarios and zone in Figure 2.

Table 1. Area of floodplain inundation for the ARIs under the two scenarios for a zone, as an example of the style of output from MDB-FIM

\begin{tabular}{lccc}
\hline ARI & $\begin{array}{c}\text { Scenario A } \\
\text { Area ha) }\end{array}$ & $\begin{array}{c}\text { Scenario B } \\
\text { Area (ha) }\end{array}$ & $\begin{array}{c}\text { Difference } \\
\mathbf{( \% )}\end{array}$ \\
\hline 1 -in-1 & 194,347 & 105,515 & 45.7 \\
1 -in-2 & 338,567 & 212,904 & 37.1 \\
1 -in-5 & 433,379 & 303,378 & 30.0 \\
1 -in-10 & 445,956 & 342,699 & 23.2 \\
\hline
\end{tabular}

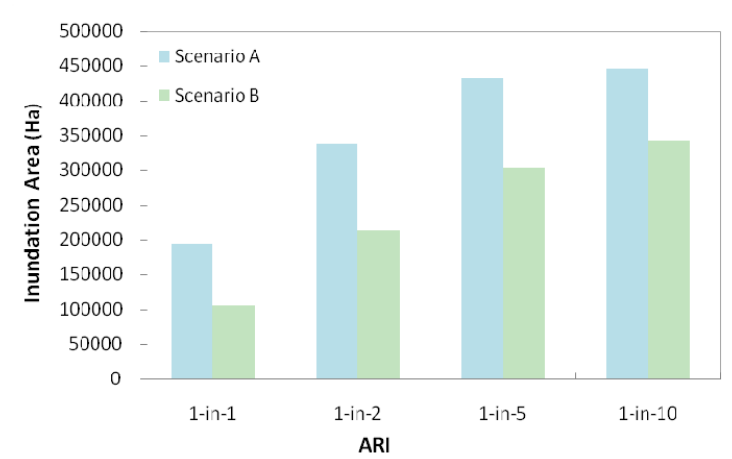

Figure 4. Comparison of inundation areas for the ARIs under the two scenarios for a zone (data in Table 1).

\subsection{Inundation Timing}

The flood frequency analysis results in a series of look-up tables containing the ARIs (ML/day) for each flow scenario (Table 2 and Figure 5). These ARIs provide a metric of change in flows associated with particular return periods (columns 2 and 3, Table 2); and in change in return periods of flows of a certain volume (Column 4, Table 2) which can be estimated using the same RPCs created from the flood frequency analysis. From the example data in Table 2, it is clear that the size of environmentally relevant flow events has been reduced, thus compromising the extent of inundation. Flow events of the size experienced under Scenario A (assuming that the scenario is a reconstruction of an historical flow sequence) are temporally compromised, with the historical 1-in-10 ARI flow rate only being achieved once in 20 years under the scenario under evaluation (Scenario B). This may have significant environmental consequences.

Table 2. Flows associated with the four ARIs for two scenarios, demonstrating how ARIs capture the change in (annual) timing of environmentally relevant flow events (noting that these data are hypothetical). Column 4 contains the revised ARIs for Scenario B to achieve the flows associated with the four ARIs

\begin{tabular}{cccc}
\hline ARI & $\begin{array}{c}\text { Scenario A } \\
\text { (ML/day) }\end{array}$ & $\begin{array}{c}\text { Scenario B } \\
\text { (ML/day) }\end{array}$ & Revised ARI \\
\hline 1-in-1 & 9,448 & 8,352 & 1 -in-1.6 \\
1 -in-2 & 23,997 & 21,663 & 1 -in-4.2 \\
1 -in-5 & 28,972 & 26,851 & 1 -in-9 \\
1-in-10 & 31,409 & 29,589 & 1 -in-20 \\
\hline
\end{tabular}

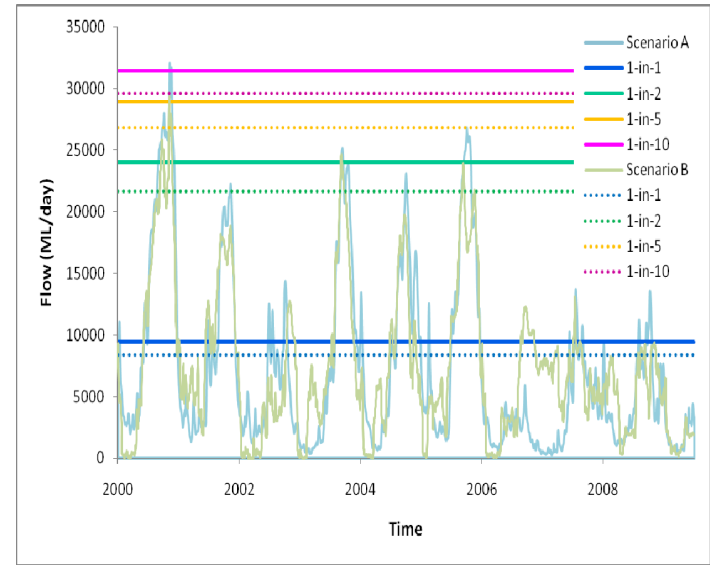

Figure 5. Comparison of flows associated with the four ARIs under the two scenarios for a zone. 
Finally, the timing, lateral extent, period and depth of inundation are the characteristics of flood connectivity which are vital to wetlands and floodplain ecosystems. As essential inputs to ecological response models, critical information extracted from MDB-FIM in relation to area and timing of inundation and flows indicate the likelihood of inundation. These data can be integrated with other ecological components, such as habitat locations of vegetation, birds and frogs, for decision-making on where targeted environmental watering is most crucial to prevent decline of wetlands and floodplain ecosystems. This is the focus of on-going research of this project.

\section{CONCLUSIONS}

The ability of MDB-FIM to derive change in return periods of environmentally relevant flows is useful in determining whether parts of the floodplain that have historically received water under particular flow events will receive water under alternate flow scenarios. The current method of associating flow peaks with inundation extent maps provides baseline evidence for understanding the relationship between flow, its timing, and extent. It is useful in considering the implications of changes in flow delivery on the extent of mapping. This may be quite profound when considering climate change scenarios with reduced inflows. Discussion of the use of MDB-FIM for climate change modelling is described in Doody et al. (2009).

The method is less sensitive to changes in the delivery of water (i.e. inter-annual distribution and duration of events). The use of ARIs is useful, but not sufficient - we need to develop a temporal metric that captures the inter-annual dimension (a dimensioned ARI (dARI)). MDB-FIM could then be more sophisticated in associating maps of inundation extent with dARIs, which would extend its ability to differentiate flow scenarios that are similar in terms of volume of water but different in terms of the timing of delivery of that water.

The planning for, and management of, water delivery to floodplains and wetlands is a complex business. Not only does it require an understanding of the implications on other potential uses of that water (e.g. town water supply, irrigation, infrastructure maintenance), it also requires estimating the costs and benefits of the delivery. This is always the case, irrespective of whether the country is facing extreme events (drought or flood). In times of shortages, water needs to be managed efficiently and effectively.

Within the Basin, the complexity has been recognized and high level policy direction is being provided through the Water Act 2007 and the consequent Basin Plan, which will prescribe limits on water diverted for consumption (and water for the environment). MDB-FIM can assist with providing relationships between flow events and inundated areas to support an assessment of the ecological consequences of the Basin Plan.

\section{ACKNOWLEDGMENTS}

The initial and ongoing core development of MDB-FIM has been funded by the CSIRO's Water for a Healthy Country Flagship. The additional development to meet the needs of the Basin Plan assessment is funded through a partnership with the Murray-Darling Basin Authority. We would also like to acknowledge the original MDB-FIM team leaders, Ian Overton and Tanya Doody, for their foresight and vision.

\section{REFERENCES}

Ceccato, P., S. Flasse, and J-M Grégoire (2002). Designing a spectral index to estimate vegetation water content from remote sensing data: Part 2. Validation and applications. Remote Sensing of Environment, 82, 198-207.

Doody T.M., I.C. Overton, and D. Pollock (2009). Floodplain inundation mapping. Chapter 19 In Overton, I.C., M.J. Colloff, T.M. Doody, B. Henderson and S.M. Cuddy (eds). Ecological Outcomes of Flow Regimes in the Murray-Darling Basin. Report prepared for the National Water Commission by Water for a Healthy Country Flagship, CSIRO, Canberra, 287-307.

Guerschman, J.-P., N. Sims, G. Warren, T. Arthur, and M. Colloff (2009). Remote sensing of inundation. Chapter 18 In I.C. Overton, M.J. Colloff, T.M. Doody, B. Henderson and S.M. Cuddy (eds.) Ecological Outcomes of Flow Regimes in the Murray-Darling Basin. Report prepared for the National Water Commission by Water for a Healthy Country Flagship, CSIRO, Canberra, 271-286.

Huete, A., K. Didan, T. Miura, E.P. Rodriguez, X. Gao, and L.G. Ferreira (2002). Overview of the radiometric and biophysical performance of the MODIS vegetation indices. Remote Sensing of Environment, 83, 195-213.

Kirby, M., A.I.J.M. van Dijk, M. Mainuddin, J. Peña-Arancibia, J.P. Guerschman, Y. Liu, S. Marvanek, D.L. McJannet, Z. Paydar, T.R. McVicar, T.G. Van Niel, and L.T. Li (2008). River water balance accounts 
across the Murray-Darling Basin, 1990-2006. A report to the Australian Government from the CSIRO Murray-Darling Basin Sustainable Yields Project. CSIRO, Canberra, Australia.

Overton, I.C., T.M. Doody, Y. Chen, D. Pollock and N. Sims (2011). Murray-Darling Basin Floodplain Inundation Model (MDB-FIM). Technical report. Water for a Healthy Country Flagship report, CSIRO, Adelaide.

Overton, I.C., K. McEwan, and J.R. Sherrah (2006). The River Murray Floodplain Inundation Model - Hume Dam to Lower Lakes. Water for a Healthy Country Flagship Report, CSIRO, Adelaide.

Penton, D.J., and I.C. Overton (2007). Spatial Modelling of Floodplain Inundation Combining Satellite Imagery and Elevation Models. In MODSIM 2007 International Congress on Modelling and Simulation, December 2007, Oxley, L. and Kulasiri, D., (Eds.), Modelling and Simulation Society of Australia and New Zealand, 1464-1470.

USGS (2010). MOD09A1 Product page. United States Geological Service \& NASA, Land Process Distributed Active Archive Centre MODIS Product Table. https://lpdaac.usgs.gov/lpdaac/products/modis_products_table/surface_reflectance/8_day_13_global_500m $/$ mod09a1 (accessed 02.08.10). 